\title{
Article \\ Can Clean Heating in Winter in Northern China Reduce Air Pollution?-Empirical Analysis Based on the PSM-DID Method
}

\author{
Si Wang ${ }^{1}$, Qiaojie Huang ${ }^{1}$, Qiang Liu $^{2}$ and Demei Sun ${ }^{1, *}$ \\ 1 School of Economics and Management, Harbin Engineering University, Harbin 150009, China; \\ huang211@hrbeu.edu.cn (S.W.); huangqj2022@126.com (Q.H.) \\ 2 School of Economics and Management, Liaoning University of Technology, Anshan 121001, China; \\ xq1986625@163.com \\ * Correspondence: 15730174729@163.com; Tel.: +86-157-3017-4729
}

Citation: Wang, S.; Huang, Q.; Liu, Q.; Sun, D. Can Clean Heating in Winter in Northern China Reduce Air Pollution?-Empirical Analysis Based on the PSM-DID Method. Energies 2022, 15, 1839. https:// doi.org/10.3390/en15051839

Academic Editors: Lean Yu, Xiaofeng $\mathrm{Xu}$ and Francesco Nocera

Received: 28 January 2022

Accepted: 25 February 2022

Published: 2 March 2022

Publisher's Note: MDPI stays neutral with regard to jurisdictional claims in published maps and institutional affiliations.

Copyright: (c) 2022 by the authors. Licensee MDPI, Basel, Switzerland. This article is an open access article distributed under the terms and conditions of the Creative Commons Attribution (CC BY) license (https:// creativecommons.org/licenses/by/ $4.0 /)$.

\begin{abstract}
In northern China, a large volume of coal is consumed for heating in winter, resulting in frequent smog and air pollution, which has a serious effect on people's health and quality of life. Clean heating is a national important livelihood strategy related to residents' warmth. Whether haze weather can be effectively reduced and whether the heating energy structure can really be improved needs to be verified. This study takes 115 heating cities in the northern area as the research objects, takes 12 pilot cities implementing clean heating policy as the treatment group, employs the Propensity Score Matching method to match the non-pilot cities to get the reasonable control group city, uses the double-difference method to carry out the quantitative test on the implementation effect of the clean heating policy. The results show that clean heating in northern China reduces the air pollution in winter, and the air pollution level in winter decreases $46.6 \%$ after the implementation of the policy. Clean heating is an effective environmental regulation method that can control the level of winter air pollution from the source.
\end{abstract}

Keywords: clean heating; air pollution; PSM-DID

\section{Introduction}

Clean heating is a policy that benefits about 500 million people in 15 provinces. It mainly refers to the use of clean energy such as natural gas and electric power, combined with the construction of a heat supply network and energy-saving buildings can realize low emission and low pollution heating. Northern China, which has a rigid demand for heating in winter, covers about $70 \%$ of the land area. However, for a long time, the ratio of clean heating in some areas was relatively low, especially in towns and rural areas, where a large number of scattered coal burning and low-efficiency small boilers are used for heating in winter, which aggravates the severity of air pollution. Studies have confirmed that the main cause of winter haze is the pollution caused by heating in winter emissions [1]. At the fourteenth meeting of the central financial and economic leading group, General Secretary Xi Jinping emphasized the importance of promoting clean heating in the northern part of the country. It is important to the residents in the northern region to for heating, haze reduction, energy production, and consumption revolution.

Since 2013, a series of policies issued by the State Council and relevant ministries have involved the support for clean heating. City governments at all levels have actively promoted the construction of clean heating facilities. Considering the importance and urgency of air pollution prevention and control, the Ministry of Environmental Protection formulated the "work plan for air pollution prevention and control in Beijing, Tianjin and Hebei and surrounding areas in 2017" and defined the scope of the air pollution transmission channel in Beijing-Tianjin-Hebei Region, namely " $2+26$ " cities. In the same year, the Government of China selected 12 cities from the " $2+26$ " cities. Tianjin and Shijiazhuang were used as the first batch of winter clean heating pilot projects in northern 
China, which clearly promoted the clean heating work in winter in northern China. At present, the clean heating rate of the first batch of clean heating pilot cities is close to $90 \%$ [2], but the policy effect of clean heating is still relatively vague. Does clean heating reduce air pollution? Can the pilot project of clean heating be used as a demonstration city to realize the "win-win" of economic development and environmental quality? Which factors affect the implementation effect of clean heating? How to promote the further implementation of clean heating? This study will systematically analyze and discuss these problems. These problems cannot be ignored and need to be solved urgently.

Scholars' studies on winter heating mainly focus on the current situation of heating [3,4], heating systems and applications [5-7], heating modes [8], impact on air pollution, etc. [1,9-11], and achieved fruitful research results. Among them, there are two main directions about the influence of winter heating on air pollution: one is the direct relationship between central heating and air pollution. Scholars have found that the traditional central heating mode based on coal and straw has a significant negative impact on air quality. Chen et al. [12] used the Qinling Huaihe River as the dividing line for the central heating policy, analyzed the panel data of 90 heating cities in the south and north over the past 20 years by using the breakpoint regression method, and found that the suspended solids particles in the northern region were 55\% higher than those in the south. Chen et al. [10] focused on the impact of coal heating on air quality in winter in northern China. Through breakpoint regression analysis, it was found that the impact on air pollution was relatively weak when heating was just started. However, with the increase in coal consumption, air pollutants would continue to accumulate, which led to the enhancement of the pollution effect. Li et al. [11] estimated the relationship between central heating and air pollution using the breakpoint regression method from the time dimension analysis and concluded that central heating had a significant negative impact on air pollution, and the concentration of various air pollutants increased significantly during the heating period. In addition, some scholars have also used other methods to carry out research. Chen et al. [12] used the random effect model to study the Spring Festival effect of urban air quality in China. It was found that the air pollution level in the central heating areas was 37.04\% higher than that in the non-central heating areas, indicating that central heating was an important reason affecting air quality. The other is to study the influence of air pollution caused by heating on human health. Bellander et al. [13] investigated the relevant historical data of Stockholm, Sweden, and analyzed the impact of air pollution caused by household heating on male lung cancer. Chen et al. [9] found that the high concentration of suspended solids particles produced by coal combustion reduced the life expectancy of people in northern China by 5.5 years. Zhao et al. [14] used a stratified random cluster sampling method to select 536 elderly people in Jilin Province exposed to different degrees of air pollution as the research objects and further analyzed the negative impact of air pollution on the elderly respiratory system health during the heating period.

With the development of new energy technology and the implementation of the clean heating policy, some scholars have carried out research on clean heating. The main research results focused on the heating mode, efficiency, technology, and economy. First, the clean heating mode and efficiency. Xu et al. [1] first evaluated the pollutant emission level of scattered coal heating and electric heating in the Beijing-Tianjin-Hebei region and pointed out that the pollutant emission of unit scattered coal heating was far higher than that of electric coal, but the primary energy utilization rate of electric heating was low, and the economic benefit was poor, which was not conducive to large-scale promotion. Wang et al. [15] studied the use of natural gas and air source heat pumps (ASHP) to replace household coals and coal-fired boilers for heating in Beijing-Tianjin-Hebei region and found that both natural gas and heat pump heating could significantly reduce pollutant emissions. In addition, the cost of heating retrofitting with natural gas was 14.2 yuan $/ \mathrm{kg}$ higher than with heat pumps, meaning that heat pump heating had more advantages. Zhu et al. [16] indicated that the average concentration of PM2.5 in Beijing would drop by $39 \%$ after the civil coal to gas project was completed in 2020 by the simulation analysis 
method, which had a very obvious effect on environmental improvement. Second, the technical feasibility and economic feasibility of clean heating. Qin et al. [17] analyzed the planning ideas and technical routes of clean heating in rural areas, towns, and cities. Through investigation data, Fang et al. [18] concluded several major contradictions in clean heating in northern cities, such as heat source gap, mismatch of hot spot ratio among supply, demand and low proportion of clean heat source, and further elaborated the technical route to implementing clean heating policy in northern regions.

To sum up, scholars have studied the winter heating problem from different angles. As for clean heating, scholars mostly elaborated on the development route from the engineering and technical field. Although the Chinese government has listed clean heating as an urgent issue to be solved and started the implementation of relevant policies, there are few literatures involved in the systematic analysis of the implementation effect of the clean heating policy in the field of theoretical research. Therefore, this study applies the Propensity Score Matching-Difference-in-difference method to analyze the first batch of clean heating pilot cities and quantitatively evaluate the impact of the implementation of the clean heating policy in winter on the air pollution level in northern cities. Compared with the previous literature, the main innovation of this study lies in that: first, as for research content, the literature on the impact of clean heating policy on air quality is relatively limited, this study enriches the relevant research. Second, in terms of research methods, this study uses propensity score matching for the first time to obtain the control group of the first batch of pilot cities from 115 heating cities, which overcomes the endogenous problem. In addition, in terms of data selection, this study does not directly use the annual average data of air pollution level but chooses to study the average value of the winter heating period, which makes the conclusion more representative. Finally, in the selection of control variables, due to the poor availability of the actual total urban population data, this study uses "urban domestic waste production" instead of "permanent population" to reduce the error caused by the lack of data.

\section{Materials and Methods}

Scholars usually use the Difference-in-difference method (DID) to evaluate the effect of policy implementation [19]. As an environmental policy benefiting the northern region, the implementation of the clean heating policy provides a good "quasi-natural experiment" for this study to adopt the Difference-in-difference method. The main idea is to take the year of the pilot city of clean heating as the initial year of the experiment and detect the differences in air pollution emissions before and after the implementation of the policy; that is, the policy effect of clean heating. The DID model is designed as follows:

$$
y_{i t}=\alpha_{0}+\alpha_{1} d t_{i t}+\alpha_{2} \operatorname{TREAT} T_{i t}+\alpha_{3} T R E A T_{i t} d t_{i t}+\alpha_{4} X_{i t}+\varepsilon_{i t}
$$

where $d t$ is the time dummy variable and TREAT indicates the regional dummy variable. $d t=0$ represents the period before the implementation of the policy, $d t=1$ represents for the period after the implementation of the policy, where TREAT $=1$ refers to a given city implementing the policy and 0 otherwise. $y_{i t}$ represents the air quality index of area $I$ in year $t ; X_{i t}$ is the control variable. The air quality index (AQI) of the treatment group before and after the implementation of the clean heating policy is $\alpha_{0}+\alpha_{2}$ and $\alpha_{0}+\alpha_{1}+\alpha_{2}+\alpha_{3}$, respectively, with a change in $\alpha_{1}+\alpha_{3}$, while the control group's AQI is $\alpha_{1}$. In order to make the coefficient before TREAT $i t t_{i t}$ equal to the clean heating policy effect of the treatment group, it is necessary to make the $\alpha_{1}$ of the two groups equal. It can be seen that the premise of DID model is that the change trend in air pollution emissions in the treatment group and control group is equal.

However, due to the systematic differences between the two groups before the reform time point, the differences in pollution control levels between the two groups of ordinary cities cannot be regarded as the average treatment disposal effect of the clean heating policy. If we can simultaneously observe the air quality index of each pilot city before and after 
the implementation of clean heating, then the differences between the two states are the causal effect of the reform.

However, the actual situation cannot fully meet the precondition of DID. We cannot obtain the differences in pollution levels in the two states at the same time. Therefore, this study uses the PSM-DID (propensity score matching difference-in-differences) method to establish a "counterfactual framework" to modify the DID results.

Heckman et al. proposed the propensity score matching method was proposed by Heckman et al. Its basic idea is to match the estimated value. Assuming that city "i" belongs to the processing group, a city " $\mathrm{j}$ " is selected from the control group so that the characteristic variables of individual $\mathrm{i}$ and $\mathrm{j}$ can match as much as possible, that is, $x_{i} \approx x_{j}$. Therefore, according to the principle of parallel trend hypothesis, the probability of individuals $i$ and $\mathrm{j}$ being selected into the treatment group is relatively close. Then, the cities selected as the implementation pilot of the clean heating policy need to select a "city that should be selected into the clean heating city pilot project but has not implemented the policy", thus forming a "counter-fact" framework.

The specific steps of the PSM method are as follows: First, select the key factors that determine whether a city is selected as a clean heating pilot city as the matching criterion. Second, establish a Logit model to find the probability of each city implementing a clean heating policy, match the treatment group and the control group based on the propensity score value, and obtain a new set of samples as a feasible control group. The Logit model is set as follows:

$$
Y_{i t}=\beta_{0}+\beta_{1} x_{i t}+\varepsilon_{i t}
$$

where $Y_{i t}$ represents for the probability value of sample city $i(\mathrm{i}=1,2 \ldots \mathrm{n})$ at time $t$ (propensity matching value). $x_{i t}$ is the set of control variables that affect whether the policy is implemented, which are constant terms and variable coefficients, $\varepsilon_{i t}$ is the random error term. Through Formula (2), we can estimate the probability of each heating city becoming a clean heating pilot city.

\section{Results and Discussion}

\subsection{Data Sources}

Among the cities in northern China, excluding some cities with significant differences in economic development and air quality and serious data missing, 115 heating cities in northern China were selected as the sample. Combined with the policy implementation year, the short panel data of each city from 2014 to 2019 were used as the final data source. The original data of the explained variable AQI was from the daily historical data of the China environmental monitoring website, and the original data of control variables were all from the 2014-2019 statistical yearbook and some annual reports of the Chinese municipal and provincial administrative regions. As part of the annual data for 2019 was not available, the missing values were filled by the regression interpolation method by analyzing the monthly reports of each city or based on previous research data. At the same time, in order to reduce the impact of heteroscedasticity on the model, the data of some variables were logarithmic processed (as shown in Table 1).

\subsection{Variable Selections}

\subsubsection{Interpreted Variables Settings}

Since only one kind of air pollutant, such as $\mathrm{SO}_{2}, \mathrm{PM} 2.5$, etc., covers the limited air pollution range, it is not possible to comprehensively assess the air quality situation. Therefore, it is necessary to select a relatively authoritative comprehensive index that is widely recognized by relevant researchers and can fully reflect the air quality. In 2012, the National Environmental Protection Agency re-established the Air Quality Index (AQI) based on the newly revised Ambient Air Quality Standards to make up for the lack of the Air Pollution Index (API). Six pollutants, including fine particulate matter (PM2.5), inhalable particulate matter (PM10), and sulfur dioxide (SO2), are included in the evaluation system and updated every hour. AQI is a dimensionless index formulated by the Ministry 
of Environmental Protection to describe air quality quantitatively and has been adopted by a large number of scholars due to its high authority and comprehensive and timely release. Therefore, this paper took the annual average AQI of each city in winter as the main parameter to measure air pollution. The lower the index, the better the air quality.

Table 1. Main variables and the specific calculation methods.

\begin{tabular}{|c|c|c|c|c|c|}
\hline Category & Vari & ble & Index & Symbol & Unit \\
\hline $\begin{array}{l}\text { Dependent } \\
\text { variable }\end{array}$ & Air quality level & Air quality index & $\begin{array}{l}\text { Monthly average value of } \\
\text { air quality index during } \\
\text { the heating period in } \\
\text { various regions }\end{array}$ & AQI & - \\
\hline \multirow{2}{*}{$\begin{array}{l}\text { Core explana- } \\
\text { tory variable }\end{array}$} & \multirow{2}{*}{$\begin{array}{c}\text { Policy } \\
\text { dummy variable }\end{array}$} & $\begin{array}{l}\text { Regional dummy } \\
\text { variable }\end{array}$ & $\begin{array}{c}\text { Whether the region has } \\
\text { implemented a clean } \\
\text { heating policy }\end{array}$ & TREAT & - \\
\hline & & $\begin{array}{l}\text { Time dummy } \\
\text { variable }\end{array}$ & $\begin{array}{l}\text { Whether a clean heating } \\
\text { policy is implemented } \\
\text { during this period }\end{array}$ & $\mathrm{Dt}$ & - \\
\hline \multirow{7}{*}{ Control variable } & \multirow{3}{*}{$\begin{array}{c}\text { Urban economic } \\
\text { development level }\end{array}$} & Economic scale & $\begin{array}{l}\text { Take the } 2014 \text { GDP as the } \\
\text { base period to deflate the } \\
\text { logarithm of each } \\
\text { year's GDP }\end{array}$ & GDP & $\begin{array}{l}\text { Per ten } \\
\text { thousand yuan }\end{array}$ \\
\hline & & Car ownership & $\begin{array}{l}\text { Logarithm of the actual } \\
\text { number of private car } \\
\text { ownership in the region }\end{array}$ & CL & $\begin{array}{l}\text { Per ten } \\
\text { thousand vehicles }\end{array}$ \\
\hline & & $\begin{array}{c}\text { Domestic waste } \\
\text { production }\end{array}$ & $\begin{array}{l}\text { Subject to the data } \\
\text { disclosed in the annual } \\
\text { report and } \\
\text { statistical yearbook }\end{array}$ & DG & $\begin{array}{l}\text { Per ten } \\
\text { thousand tons }\end{array}$ \\
\hline & \multirow{2}{*}{$\begin{array}{l}\text { Urban energy } \\
\text { structure status }\end{array}$} & $\begin{array}{c}\text { Energy } \\
\text { consumption }\end{array}$ & $\begin{array}{l}\text { Ratio of urban industrial } \\
\text { output value/provincial } \\
\text { industrial output } \\
\text { value * Provincial } \\
\text { energy consumption }\end{array}$ & $\mathrm{NC}$ & $\begin{array}{c}\text { Per ten } \\
\text { thousand tons of } \\
\text { standard coal }\end{array}$ \\
\hline & & $\begin{array}{l}\text { Coal consumption } \\
\text { as a proportion of } \\
\text { total energy } \\
\text { consumption }\end{array}$ & $\begin{array}{l}\text { The ratio of coal } \\
\text { consumption to } \\
\text { total regional } \\
\text { energy consumption }\end{array}$ & SEC & $\%$ \\
\hline & \multirow{2}{*}{$\begin{array}{l}\text { Geo-climatic } \\
\text { conditions }\end{array}$} & $\begin{array}{l}\text { Monthly average } \\
\text { wind speed }\end{array}$ & $\begin{array}{l}\text { Average monthly wind } \\
\text { speed during heating } \\
\text { period in winter }\end{array}$ & AWS & $\mathrm{m} / \mathrm{s}$ \\
\hline & & $\begin{array}{l}\text { Average monthly } \\
\text { precipitation }\end{array}$ & $\begin{array}{c}\text { Average monthly } \\
\text { precipitation during } \\
\text { winter heating period }\end{array}$ & AAR & $\mathrm{mm}$ \\
\hline
\end{tabular}

Note: * represents the significance level of $10 \%$.

\subsubsection{Core Explanatory Variables Settings}

The implementation of the clean heating policy (TREAT*Dt) is the product of the regional virtual variable (TREAT) and time virtual variable (Dt), which represents the net policy effect of the clean heating policy. The virtual variable is measured by $(0,1)$. The city that has implemented clean heating is regarded as the city of treatment group, and the value is 1 ; otherwise, it is 0 . 


\subsubsection{Control Variables and Measurement Indicators Settings}

This study mainly considered three types of factors to identify the control group: the level of urban economic development, urban energy development, and geographic and climatic conditions. Research showed that these three factors might have impacts on urban air quality. First, the Environmental Kuznets Curve points out that the relationships between economic development and environmental pollution present an inverted " $U$ " curve, that is, in the early stage, environmental pollution is at a higher level; when the economic development level reaches a certain stage, environmental pollution begins to decline with the increase in per capita income. Second, cities with a relatively high proportion of energy, such as wind power, hydropower, and solar energy, rely less on primary energy sources, such as coal, thus reducing the diffusion of pollutants and reducing the impact on air quality. In addition, the city's climate, geographical conditions, and other natural factors will directly affect the diffusion of air pollutants. For example, higher wind speed and sufficient precipitation will improve the air quality of the city [20].

The measurement indexes of each variable were as follows:

- Economic scale (denoted by "GDP")

Relevant research showed that the economic scale and pollution level of a city have a mutual influence on each other [21]. On the one hand, in the process of urban development, due to the continuous improvement of the living standards of urban residents, the consumption of various resources and energy increases, and the emission of pollutants also increases. On the other hand, economic development can promote technological progress and optimize the industrial structure, thereby reducing the environmental pollution. Since the growth of nominal GDP is generally faster than that of real GDP, this study used 2014 as the base period to obtain the real GDP of each city to reduce the error. The original data for the calculation came from the China Statistical Yearbook published by the National Bureau of Statistics.

\section{- Car ownership (denoted by "CL")}

With the increase in social per capita personal assets, the number of personal cars is increasing rapidly. The China Motor Vehicle Environmental Management Annual Report showed that China is the world's largest motor vehicle producer and marketing country. Vehicle exhaust emissions have significant impacts on urban air quality. This study selected the car ownership of each city over the years as the control variable from the China City Statistical Yearbook.

\section{- Domestic waste production (denoted by "DG")}

Residents are one of the important subjects of the urban economy and energy consumption. However, urban energy consumption is not limited to the permanent population. It depends on the total population within a period. Considering that the total population data were difficult to obtain, and when income and expenditure levels are similar, the amount of domestic waste per capita in different cities is positively correlated with the number of the population [22], this study took the amount of urban domestic waste generated instead of the permanent population as the control variable. The data came from the annual report on the prevention and control of solid waste pollution in large and medium-sized cities and the statistical yearbook of each city.

\section{- Energy consumption (denoted by "NC")}

Although the factors that cause air quality change are complex, there is quite a lot of literature $[23,24]$ that point out that the process of energy consumption is often accompanied by the discharge of a large number of air pollutants, so there is a certain correlation between energy consumption and air quality. Since China's industrial energy consumption accounts for about 70\% of China's total energy consumption [25] and considering the availability of data, this paper first calculated the ratio of urban industrial output value to provincial industrial output value and then took the product of the result and energy consumption as the energy consumption of each city. Among them, the coal consumption data came from 
the China Statistical Yearbook published by the National Bureau of Statistics (Available online: http:/ / www.stats.gov.cn/tjsj./ndsj/, accessed on 16 January 2022).

- Share of total energy consumption (denoted by "SEC")

The increase in coal consumption will lead to an increase in pollutant emissions, and coal consumption has the most significant impact on exhaust gas emissions [26]. Due to the differences in urban volume, this study used the proportion of coal consumption in total energy consumption as the control variable.

- Monthly average wind speed (denoted by "AWS")

According to relevant research and analysis, there is an obvious correlation between air quality and meteorological elements [27]. The greater the wind speed and the more precipitation there is, the better the air quality is. Moreover, Li et al. [28] pointed out that the main meteorological factors affecting air quality in different seasons were different. In winter, the average wind speed and precipitation became the most explanatory index of AQI variation. Relevant data came from the China Meteorological Administration (Available online: http:/ / www.cma.gov.cn/, accessed on 16 January 2022).

The main variables and the specific calculation methods are shown in Table 1.

\subsection{PSM-DID Method Analysis}

\subsubsection{Parallel Trend Test}

In order to accurately identify the promotion effect of the clean heating policy on reducing urban air pollution, before estimating the dual difference model, this study needed to examine whether the sample met the parallel trend hypothesis. That is, whether the change trend of the average air quality index of the experimental group and the control group was consistent before the implementation of the clean heating policy. Therefore, this study selected the logarithm of the average air quality index of the experimental group and the control group cities in winter from 2014 to 2019. The trend chart obtained is shown in Figure 1.

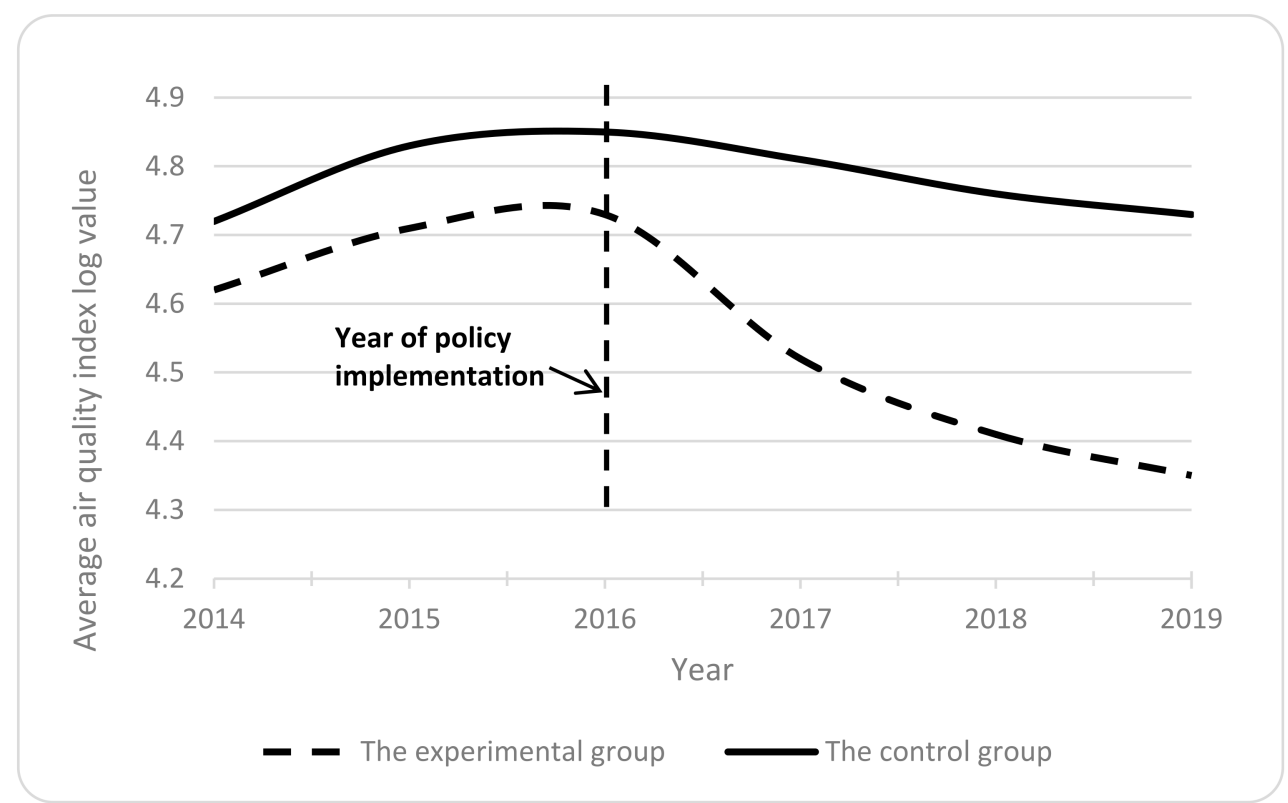

Figure 1. Air quality index change trend.

The image on the left side of the dotted line in Figure 1 shows that before the implementation of the clean heating policy, the air quality index of the experimental group and the control group showed a steady upward trend, and the trends were basically the same. The results showed that the sample basically met the parallel trend before the implementation 
of the clean heating policy; the image on the right side of the dotted line shows that after the implementation of the clean heating policy, the air quality index of the experimental group and the control group both showed a downward trend. Although the air quality index of the former fell more than the latter, the differences were not large. It showed that the sample basically met the parallel trend after the implementation of the clean heating policy. The results showed that the experimental and control groups after PSM matching could meet the parallel trend hypothesis, and the clean heating policy could cause the air quality index of pilot cities to decline more significantly.

\subsubsection{Matching Effect Analysis}

In this study, the Logit model was used to calculate the matching scores of 115 cities. The main methods of propensity matching included Nearest Neighbor Matching, Mahalanobis distance radius matching, and kernel matching, etc. Among them, the kernel matching method can make full use of all the control samples and make better use of the data. Therefore, we selected kernel matching as the propensity matching method. Propensity score matching requires that the score distribution pattern of variable matching used by the model remains consistent, with no significant differences. As can be seen from Table 2, the error reduction percentage obtained by evaluating the matching results through matching was relatively high, and there were no differences in the mean value between the two groups of samples. The result showed that the matching quality was better.

Table 2. Error reduction after matching.

\begin{tabular}{|c|c|c|c|c|c|c|c|}
\hline Variables & Sample & $\begin{array}{c}\text { Mean of } \\
\text { Treatment Group }\end{array}$ & $\begin{array}{c}\text { Mean of } \\
\text { Control Group }\end{array}$ & $\begin{array}{l}\text { Standard } \\
\text { Error }(\%)\end{array}$ & $\begin{array}{c}\text { Error } \\
\text { Reduction (\%) }\end{array}$ & T Value & $p>t$ \\
\hline \multirow{2}{*}{ GDP } & Before matching & 5.521 & 5.448 & 23.885 & \multirow{2}{*}{50.65} & 6.59 & 0.00 \\
\hline & After matching & 5.521 & 6.227 & 6.554 & & 2.21 & 0.142 \\
\hline \multirow{2}{*}{ CL } & Before matching & 3.877 & 4.556 & 44.663 & \multirow{2}{*}{70.65} & 3.521 & 0.00 \\
\hline & After matching & 3.877 & 3.987 & 4.102 & & 0.54 & 0.369 \\
\hline \multirow{2}{*}{ DG } & Before matching & 4.267 & 3.855 & 6.367 & \multirow{2}{*}{68.21} & 4.418 & 0.01 \\
\hline & After matching & 4.267 & 3.611 & 3.381 & & 1.12 & 0.227 \\
\hline \multirow{2}{*}{$\mathrm{NC}$} & Before matching & 4.548 & 5.561 & 6.691 & \multirow{2}{*}{70.14} & 5.521 & 0.02 \\
\hline & After matching & 4.548 & 5.521 & 2.049 & & 1.15 & 0.44 \\
\hline \multirow{2}{*}{ SEC } & Before matching & 88.784 & 82.416 & 3.099 & \multirow{2}{*}{84.12} & 4.478 & 0.00 \\
\hline & After matching & 88.784 & 84.563 & 1.987 & & 2.23 & 0.125 \\
\hline \multirow{2}{*}{ AWS } & Before matching & 23.447 & 16.345 & 2.952 & \multirow{2}{*}{88.22} & 2.09 & 0.00 \\
\hline & After matching & 23.447 & 20.339 & 1.237 & & 4.41 & 0.65 \\
\hline \multirow{2}{*}{ AAR } & Before matching & 45.667 & 39.875 & 3.552 & \multirow{2}{*}{64.47} & 3.37 & 0.03 \\
\hline & After matching & 45.667 & 42.318 & 2.458 & & 2.29 & 0.15 \\
\hline
\end{tabular}

\subsubsection{PSM-DID Model Analysis}

Taking AQI as the dependent variable, time virtual variable, regional virtual variable, and interactive term as the independent variables, the impact of policy implementation on air pollution could be directly reflected in the DID regression results. In order to test the robustness of variable coefficients, control variables were added to the original model gradually. As shown in Table 3, model 1 did not add any control variables, while models 2 to 8 gradually increased control variables, such as economic development level, car ownership, domestic waste production, energy consumption, the proportion of coal consumption in total energy consumption, monthly average wind speed, and monthly precipitation.

Table 3 shows that although the estimated coefficient of TREAT was different in value, the coefficient was negative, indicating that after controlling for GDP, car ownership, domestic waste production, energy consumption, coal consumption in total energy consumption, monthly average wind speed, and monthly precipitation, the air pollution levels in pilot cities that implemented clean heating policies were still significantly lower than in non-pilot cities. No matter whether the control variables were added, the estimated coefficient of Dt was positive, but the coefficient was small, which indicates that with the increase in time, 
the air pollution level of the control group did not change much. From model 1 to model 8 , the coefficient sign and significance of the core explanatory variable Dt*TREAT did not change fundamentally. Moreover, the coefficient signs of most other explanatory variables did not change significantly, and the coefficient R2 used to explain the model gradually increased. The coefficient in model 8 is discussed below.

Table 3. Estimation results of PSM-DID model.

\begin{tabular}{|c|c|c|c|c|c|c|c|c|}
\hline & (1) & (2) & (3) & (4) & (5) & (6) & (7) & (8) \\
\hline TREAT & $\begin{array}{c}-0.116^{* * *} \\
(0.021)\end{array}$ & $\begin{array}{c}-0.155^{* * *} \\
(0.022)\end{array}$ & $\begin{array}{c}-0.158^{* * *} \\
(0.023)\end{array}$ & $\begin{array}{c}-0.166^{* * *} \\
(0.024)\end{array}$ & $\begin{array}{c}-0.171^{* * *} \\
(0.025)\end{array}$ & $\begin{array}{c}-0.183^{* * *} \\
(0.026)\end{array}$ & $\begin{array}{c}-0.174^{* * *} \\
(0.027)\end{array}$ & $\begin{array}{c}-0.166^{* * *} \\
(0.028)\end{array}$ \\
\hline Dt & $\begin{array}{c}0.011^{* * *} \\
(0.028)\end{array}$ & $\begin{array}{c}0.009 * * * \\
(0.027)\end{array}$ & $\begin{array}{c}0.008^{* * *} \\
(0.026)\end{array}$ & $\begin{array}{c}0.006^{* * *} \\
(0.024)\end{array}$ & $\begin{array}{c}0.005^{* * *} \\
(0.025)\end{array}$ & $\begin{array}{c}0.005^{* * *} \\
(0.024)\end{array}$ & $\begin{array}{c}0.005^{* * *} \\
(0.025)\end{array}$ & $\begin{array}{c}0.004^{* * *} \\
(0.024)\end{array}$ \\
\hline Dt*TREAT & $\begin{array}{c}-0.216^{* * *} \\
(0.013\end{array}$ & $\begin{array}{c}-0.550 * * * \\
(0.010)\end{array}$ & $\begin{array}{c}-0.582 * * * \\
(0.011)\end{array}$ & $\begin{array}{c}-0.566^{* * *} \\
(0.008)\end{array}$ & $\begin{array}{c}-0.471^{* * *} \\
(0.009)\end{array}$ & $\begin{array}{c}-0.481^{* * *} \\
(0.008)\end{array}$ & $\begin{array}{c}-0.482 * * * \\
(0.009)\end{array}$ & $\begin{array}{c}-0.466^{* * *} \\
(0.008)\end{array}$ \\
\hline GDP & & $\begin{array}{c}0.077^{* * *} \\
(0.009)\end{array}$ & $\begin{array}{c}0.084^{* * *} \\
(0.008)\end{array}$ & $\begin{array}{c}0.065^{* * *} \\
(0.007)\end{array}$ & $\begin{array}{c}0.045^{* * *} \\
(0.009)\end{array}$ & $\begin{array}{c}0.051^{* * *} \\
(0.003)\end{array}$ & $\begin{array}{c}0.052 * * \\
(0.004)\end{array}$ & $\begin{array}{c}0.065^{* * *} \\
(0.007)\end{array}$ \\
\hline CL & & & $\begin{array}{c}0.062 * * \\
(0.009)\end{array}$ & $\begin{array}{c}0.045^{* *} \\
(0.007)\end{array}$ & $\begin{array}{c}0.052 * * \\
(0.006)\end{array}$ & $\begin{array}{l}0.044^{*} \\
(0.002)\end{array}$ & $\begin{array}{l}0.045^{*} \\
(0.003)\end{array}$ & $\begin{array}{c}0.059 * * \\
(0.007)\end{array}$ \\
\hline DG & & & & $\begin{array}{l}0.032 * \\
(0.012)\end{array}$ & $\begin{array}{l}0.031 \text { * } \\
(0.011)\end{array}$ & $\begin{array}{l}0.028 \text { * } \\
(0.006)\end{array}$ & $\begin{array}{l}0.026^{*} \\
(0.007)\end{array}$ & $\begin{array}{l}0.025 * \\
(0.012)\end{array}$ \\
\hline $\mathrm{NC}$ & & & & & $\begin{array}{l}0.033 * \\
(0.038)\end{array}$ & $\begin{array}{l}0.032 * \\
(0.025)\end{array}$ & $\begin{array}{l}0.037^{*} \\
(0.029)\end{array}$ & $\begin{array}{l}0.035 \text { * } \\
(0.028)\end{array}$ \\
\hline SEC & & & & & & $\begin{array}{c}0.078 * * \\
(0.026)\end{array}$ & $\begin{array}{c}0.065^{* *} \\
(0.027)\end{array}$ & $\begin{array}{c}0.072 * * * \\
(0.028)\end{array}$ \\
\hline AWS & & & & & & & $\begin{array}{l}0.0003 \\
(0.002)\end{array}$ & $\begin{array}{l}0.0004 \\
(0.001)\end{array}$ \\
\hline AAR & & & & & & & & $\begin{array}{l}0.0002 \\
(0.012)\end{array}$ \\
\hline $\mathrm{R} 2$ & 0.171 & 0.425 & 0.433 & 0.415 & 0.409 & 0.512 & 0.513 & 0.515 \\
\hline
\end{tabular}

Note: ${ }^{*}, * * * * *$ respectively represent the significance level of $10 \%, 5 \%$ and $1 \%$, respectively. (1)-(8) represents model (1) to model (8).

In model (8), the core explanatory variable Dt*TREAT had a significant positive effect on reducing the air quality index AQI at the $1 \%$ significance level. It showed that the implementation of the winter clean heating pilot city policy greatly promoted the control of air pollution, which reduced the winter air pollution level of the cities participating in clean heating by $46.6 \%$. This study indicates that the main reasons for the significant implementation effect of clean heating are as follows: first, the government plays a leading role in clean heating. The government mainly adopts the ordered and controlled clean heating policy. In recent years, from the central to the provincial level, dozens of powerful, relevant policies, plans, and programs have been issued, covering the determination of pilot cities of clean heating, price policies, subsidy policies, and engineering transformation and comprehensive management policies, etc. In the specific implementation, local governments have adhered to the orientation of ecological governance based on local conditions and adhered to the correct strategy of "electricity is suitable for electricity, gas for gas, coal for coal, and heat for heat" strategy. At the same time, it followed the ecological governance path of green and sustainable development, making full use of national and local subsidy policies to promote the use of coal-to-electricity, coal-to-gas, and clean coal, and combined with regional characteristics to use geothermal resources to develop multiple heating methods. Government leadership can effectively solve the "tragedy of the commons" in environmental construction, and the "task-driven" governance model can effectively achieve "concentrated efforts to do great things" [29], which is also the main reason for the efficient implementation of clean heating policies. Second, clean heating involves the interests of the diversified social subjects and obtains the cooperation of the multi-agent. Since the implementation of clean heating, relevant enterprises have been attracted to participate, especially in the fields of electricity instead of coal and gas 
for coal, which play positive roles; the hazards of air pollution have caused residents to increase their environmental awareness, health awareness, and risk awareness, and the implementation of price subsidies and other policies has promoted residents' support for clean heating. Third, the clean heating pilot cities are notably representative. The first batch of 12 pilot cities, such as Tianjin, were selected through a competitive review from the Beijing-Tianjin-Hebei and surrounding areas air pollution transmission channel " $2+26$ " cities. The review mainly considered the importance of local areas and the supply of clean heating materials, the feasibility of the implementation plan, prices and subsidies for local supporting policies, and related regulatory measures. The 12 pilot cities are mainly from Henan and Hebei provinces, of which Hebei Province accounts for five seats (including Shijiazhuang, Tangshan, Baoding, Langfang, and Hengshui), and Henan Province accounts for four seats (including Zhengzhou, Kaifeng, Hebi, and Xinxiang). These cities are mainly based on the development of heavy industry. Their industrial pillars are mostly high energy-consuming and high-polluting enterprises, such as steel, coking, and thermal power. The economy has developed rapidly, and the population density has been high. It has always been the hardest hit area by smog, and the environmental quality is poor. It is concluded that it is easy to demonstrate the effect of clean heating in practice by using regions with serious air pollution and relatively complete governance systems as pilot cities to implement clean heating.

For the control variables, at the significance level of $1 \%$, the level of urban development (GDP) had a significant negative impact on air pollution. For every unit of economic development the city increased by, the air pollution level of the city will increase by 0.065 units. The emission of pollutants in the eastern, central, and western regions of China increases with economic growth [30]. Most pilot cities belong to the Beijing-Tianjin-Hebei region and the surrounding areas. In the beginning, the " $2+26$ " cities were set up to alleviate the air pollution in Beijing-Tianjin-Hebei. At present, there is an environmental Kuznets curve of air quality in the Beijing-Tianjin-Hebei region, and the curve does not show an inverted " $U$ ". However, it is an inverted " $N$ " shape and did not reach the inflection point of the curve [31]. The reason is that the relationships between economic growth and environmental quality in the Beijing-Tianjin-Hebei region are uncoordinated and unbalanced, and the economic development path of cities in the Beijing-TianjinHebei region is still dominated by scale effect. With China's economic development entering the "new normal", it is necessary to increase the intensity of environmental regulations within an appropriate range [32]. Clean heating is a good demonstration policy, but since the effect of clean heating only appears during the heating season, a series of other environmental governance policies and specific measures are needed to achieve a fundamental improvement in the environmental quality of the pilot cities to achieve a win-win situation for economic growth and environmental protection.

The coefficient of car ownership (CL) was 0.059, which passed the significance test of $5 \%$. With every unit of car ownership increase, the air pollution level increased by 0.059 units, indicating that the higher the car ownership of urban residents is, the higher the air pollution level is. At the significance level of $10 \%$, the volume of domestic waste (DG) had a significant negative impact on air pollution. With every unit of domestic waste production increase, the air pollution level increased by 0.025 units. At the significance level of $10 \%$, energy consumption has a significant negative impact on air pollution. With every unit of energy consumption increase, the level of air pollution increased by 0.035 units. At the significance level of 5\%, the energy structure with a high proportion of industry had a significant negative impact on air pollution. For each unit of coal consumption in the total energy consumption, the air pollution level increased by 0.072 units. Most pilot cities are from Henan and Hebei, which have a large population base, a significant level of car ownership and garbage generation, and energy use mainly depends on coal, which has a significant negative impact on the environment.

In the control variables, we can see that the monthly average wind speed and monthly average precipitation in the region had no significant impact on the air pollution level of 
the city. This may be due to the fact that severe pollution tends to exist in extreme weather conditions and is unstable. For example, the static and stable weather in winter makes the horizontal and vertical diffusion capacity of the atmosphere decline, which is more likely to cause haze and other weather.

\subsection{Further Robustness Tests}

In order to verify the validity of the above test results, the robustness test was carried out. First of all, considering that the clean heating policy is a key step in the national construction of the modern energy system, its impact on air quality is affected by local policies, resource endowment, and other regional factors. With the continuous promotion of relevant government policies, departments at all levels will deepen their understanding of the implementation of clean heating. Therefore, the impact of the clean heating policy on the northern region will be closely related to time. This study needed to explore the dynamic impact of the clean heating policy. In this study, the time virtual variables were lagging one and two periods, respectively, and were substituted into the original equation for calculation. Then, the method of radius matching was adopted for the robustness test. The results are shown in Table 4.

Table 4. Robustness test based on the lag period of policy implementation.

\begin{tabular}{ccccc}
\hline $\begin{array}{c}\text { Dependent } \\
\text { Variable }\end{array}$ & Matching Method & Lag Period & Net Effect Value & T Value \\
\hline AQI & The nearest neighbor & Lag one period & $0.00675 * *$ & 1.896 \\
match $\delta=0.01$ & Lag two periods & $0.00313^{*}$ & 3.376 \\
\hline Note: ${ }^{*}$ and ${ }^{* * *}$ represent the significance level of 10\% and 1\%, respectively. & &
\end{tabular}

From Table 4, it can be concluded that the results of the robustness test results of one and two periods of policy lag were basically similar to the estimated results in the original equations, indicating that the results of the original PSM-DID are valid.

\section{Conclusions and Policy Implications}

\subsection{Conclusions}

A large volume of coal is consumed for heating in northern China in winter, which leads to frequent haze and air pollution, which seriously affects people's health and quality of life. Clean heating is a major livelihood project and popular support project of the Party Central Committee and the masses. Based on the panel data of 115 heating cities in northern China, this study applied the PSM-DID method to empirically test the impact of clean heating on air pollution in northern China.

The results of the empirical analysis demonstrated the following components: (1) In this study, the first batch of pilot cities were matched from 115 heating cities by using propensity score matching, which overcame the endogenous problem and quantitatively evaluated the positive contribution of clean heating to environmental quality improvement by using the Difference-in-difference method. Furthermore, it provided new evidence for studying the relationships between clean heating and air pollution, and it enriched the existing literature on the effect of clean heating in terms of research methods. (2) The air pollution level of the cities participating in the implementation of the clean heating policy decreased by $46.6 \%$, which shows that the clean heating policy did indeed achieve the expected effect. The reasons are that the government plays a leading role in clean heating; clean heating involves the interests of diversified social subjects and obtains the coordination of multiple subjects; the selection of pilot cities was significantly representative. (3) The level of urban development (GDP) has a significant negative impact on air pollution. The contradiction between economic growth and the environmental quality of pilot cities is still serious. In addition to clean heating, a series of other government environmental regulation policies and specific measures are needed to achieve a win-win situation between economic growth and environmental protection. (4) In addition to eco- 
nomic factors, the estimated results of other factors, such as car ownership, domestic waste production, energy consumption, and the proportion of coal consumption in total energy consumption, were consistent with expectations. With the continuous improvement in economic scale, the consumption of various resources and energy is rising, and the emission of pollutants is also increasing. Car ownership and domestic waste production directly reflect the aggravation of air pollution caused by urban residents' activities. The energy structure of the city will also affect the implementation of the clean heating policy, and the implementation of the clean heating policy in cities with a high proportion of coal consumption has a more obvious effect on reducing air pollution. In addition, the influence of monthly average wind speed and monthly average precipitation on air pollution was not significant. The geographical and climatic conditions of the city cannot continue to affect the implementation of the clean heating policy, which is more likely to aggravate air pollution in the form of extreme weather.

\subsection{Policy Implications}

The guiding significance of the research conclusions for the implementation of the clean heating policy in northern China is as follows: (1) It is necessary to give full play to the demonstration effect of pilot cities and comprehensively promote the effective implementation of clean heating in different regions according to local conditions. In recent years, relevant departments have issued a series of policies to promote clean heating in northern China: In 2017, the 13th Five-Year Plan for Energy Development and Opinions on The Price Policy of Clean Heating in Northern China pointed out that clean heating should be accelerated and regional geothermal heating and low-grade waste heat heating should be vigorously promoted; In 2018, the National Development and Reform Commission and the National Energy Administration jointly issued the Guidance on Promoting the Development of Biomass Energy Heating, which clearly speeds up the industrialization development of regional biomass energy heating to form a clean heating capacity. In 2021, the Ministry of Ecology and Environment issued a Key Plan for The Comprehensive Treatment of Air Pollution in Autumn and Winter from 2021 to 2022, mostly in northern China. Because of China's regional economic level, the government's financial strength and people's income level have a bigger difference. Regional governments should begin the current policies and regulations at the same time, combining with local resource endowment, economic level, the construction of infrastructure requirements, such as the level of system and mechanism innovation, perfecting the policy safeguard measures, promotion of high efficiency, good economy. Clean heating technology that does not rely on government subsidies can form a demonstration effect in pilot cities. (2) The government should implement regionally differentiated economic or fiscal incentives. At present, the excessive dependence on government subsidies for clean heating has caused a serious financial burden on the central and local governments. Hence clean heating should gradually reduce or even withdraw policy subsidies in good cities and related areas. It is necessary to rely on mature financial markets and introduce financial institutions to promote the transformation of clean heating from mainly relying on government subsidies to rational sharing and market operation. As a difficult area of clean heating, rural areas have many problems, such as large total energy consumption, low energy efficiency, and insufficient utilization of resources. It needs sustained policy subsidies to support it to accelerate the construction energy-saving transformation and promote the energy utilization of agricultural production waste. (3) The dominant position of enterprises in clean heating needs to be strengthened. Enterprises should be encouraged to join the clean energy heating industry, invest in clean heating projects and technology research and development, explore new business models in relevant fields of clean heating, and diversify the development trend of relevant technical routes. (4) The diversity of the energy structure of clean heating should be ensured. At present, the practice path of clean heating in northern China is similar. In urban areas, coalfired central heating is generally adopted, while in rural areas, the implementation path of "dual replacement" is mainly adopted, ignoring the utilization of local industrial waste 
heat, geothermal energy, biomass energy, and other resources. Therefore, China should give full play to the advantages of clean coal, power, natural gas, geothermal, biomass, and other clean energy, and strengthen the clean utilization of coal and the replacement of clean energy, which can not only directly reduce air pollution but also avoid the risk of heating source singleness.

Author Contributions: S.W.: Conceptualization, Methodology, Software, Validation, Formal analysis, Investigation, Resources, Data curation, Supervision, Project administration, Funding acquisition. Q.H.: Writing—original draft, Visualization. Q.L.: Resources, Writing review and editing, Project administration, Visualization, Funding acquisition. D.S.: Project administration, Funding acquisition. All authors have read and agreed to the published version of the manuscript.

Funding: This work was supported by the 2019 science research fund of the Department of Education of Liaoning Province (grant number JQW201915402), Research Base of Science and Technology Innovation Think Tank of Liaoning Province (Research Base of High Quality Development of Equipment Manufacturing Industry) (NO.09) and the 2020 Philosophy and Social Science Foundation of Heilongjiang Province of China (grant number 20JYB040).

Institutional Review Board Statement: Not applicable.

Informed Consent Statement: Not applicable.

Data Availability Statement: Not applicable.

Conflicts of Interest: The authors declare no conflict of interest.

\section{References}

1. Xu, G.; Wang, C.; Xu, C.; Bai, P. Evaluation of Air Pollutant Emissions from Scattered Coal Burning and Electric Heating in Beijing-Tianjin-Hebei Region. Res. Environ. Sci. 2016, 29, 1735-1742.

2. Li, Z. Analysis on the Technological Path of Clean Heating in Northern Rural Areas. Constr. Sci. Technol. 2017, 18, 28-31.

3. Huang, J.; Fan, J.; Furbo, S. Feasibility study on solar district heating in China. Renew. Sustain. Energy Rev. 2019, 108, 53-64. [CrossRef]

4. Song, M.; Zhu, Y.; Hao, X. Status and development suggestions of wind heating in Northern China. Energy Procedia 2017, 142, 105-110.

5. Wang, J.; Zhou, Z.; Zhao, J.; Zheng, J.; Guan, Z. Optimizing for clean-heating improvements in a district energy system with high penetration of wind power. Energy 2019, 175, 1085-1099. [CrossRef]

6. Ovchinnikov, P.; Borodinecs, A.; Millers, R. Utilization potential of low temperature hydronic space heating systems in Russia. J. Build. Eng. 2017, 13, 1-10. [CrossRef]

7. Zajacs, A.; Borodinecs, A. Assessment of development scenarios of district heating systems. Sustain. Cities Soc. 2019, 48, 101540. [CrossRef]

8. Pu, L.; Wang, X.; Tan, Z.; Wu, J.; Long, C.; Kong, W. Feasible electricity price calculation and environmental benefits analysis of the regional nighttime wind power utilization in electric heating in Beijing. J. Clean. Prod. 2019, 212, 1434-1445. [CrossRef]

9. Chen, Y.; Ebenstein, A.; Greenstone, M.; Li, H. Evidence on the impact of sustained exposure to air pollution on life expectancy from China's Huai River policy. Proc. Natl. Acad. Sci. USA 2013, 110, 12936-12941. [CrossRef]

10. Chen, Q.; Sun, F.; Xu, Y. Does Winter Heating Cause Smog? Evidence from a City Panel in North China. Nankai Econ. Stud. 2017, 4, 25-40.

11. Li, J.; Cao, J. Empirical Analysis of the Effect of Central Heating on Air Pollution in China. China J. Econ. 2017, 4, 138-150.

12. Chen, X.; Liu, Z.; Wu, P. Analysis on Chinese Urban Air Quality's' “Srping Festival Effect”: Evidence from 31 Key Cities in China. Stat. Inf. Forum 2014, 29, 57-62.

13. Bellander, T.; Berglind, N.; Gustavsson, P.; Jonson, T.; Nyberg, F.; Pershagen, G.; Järup, L. Using geographic information systems to assess individual historical exposure to air pollution from traffic and house heating in Stockholm. Environ. Health Perspect. 2001, 109, 633-639. [CrossRef] [PubMed]

14. Zhao, C.S.; Xu, M.; Li, C.G. Affecting factors related to air pollution on elderly respiratory health during heating period. Adv. Mater. Res. 2014, 955-959, 919-923. [CrossRef]

15. Wang, C.; Xu, C.; Xu, G.; Pu, B. Studies on replacing coal with natural gas and heat pump for heating in Jing-Jin-Ji region. China Environ. Sci. 2017, 37, 4363-4370.

16. Zhu, R.; Qiao, J.; Ding, B. Simulation Analysis of Environmental Impact of Replacing Civil Coal by Natural Gas in Beijing-TianjinHebei Region. Gas Heat 2018, 38, 31-34.

17. Qin, L.; Sun, J.; Chen, J. Technical Route and Case of Clean Heating Planning in Northern Heating Area. Gas Heat 2018, 38, 4-10.

18. Fang, H.; Xia, J.; Lin, B.; Jiang, Y. Research on the Status and Technical Route of Clean Heating in Northern Cities. Dist. Heat. 2018, $1,11-18$. 
19. Hu, R.; Lin, M. Developing Trend of Difference-in-Difference and Its Application in Public Policy Evaluation. Financ. Minds 2018, $3,84-111$.

20. Ma, L.; Shi, D. Study on Green Collaborative Development Process of Beijing-Tianjin-Hebei Region through Re-Examination of Spatial Environmental Kuznets Curve. China Soft Sci. 2017, 10, 82-93.

21. Zhai, L.; Zhao, R. Analysis of the Relationship between Economic Growth, Energy Intensity and Air Pollution. Soft Sci. 2019, 33, 60-66.

22. Wang, T.; Lu, Z. Population Growth, Income Level and Urban Environment. China Popul. Resour. Environ. 2012, $22,143-149$.

23. Song, H.; Sun, Y.; Chen, D. Assessment for the Effect of Government Air Pollution Control Policy: Empirical Evidence from "Low-carbon City" Construction in China. Manag. World 2019, 6, 95-195.

24. Lin, B.; Li, J. Transformation of Chinas energy structure under envioronmental governance constraints: A peak value analysis of coal and carbon dioxide. Soc. Sci. China 2015, 9, 84-107.

25. Chen, N.; Xu, Y. An empirical analysis on the influencing factors of Haze pollution in Beijing. China's Popul. Resour. Environ. 2016, $26,73-76$.

26. Tian, S.; Zhao, P. Coal consumption, pollution emissions and regional economic growth. Inq. Econ. Issues 2017, 3, $170-177$.

27. Zhang, J.; Wang, Y.; Gao, S.; Cheng, L.; Mao, J.; Sun, Y.; Ma, Z.; Xiao, J.; Zhang, H. Study on the relationship between meteorological elements and air pollution at different time scales based on KZ filtering. China Environ. Sci. 2018, 38, 3662-3672.

28. Li, S.; Du, H.; Wu, Z.; Guo, X.; Yang, Y. Characteristics of air quality change and its driving factors in Beijing-Tianjin-HebeiShandong-Henan region. Environ. Pollut. Control 2018, 40, 1431-1435.

29. Wei, N.; Meng, Q. Mechanism and Institutional Logic of Cross-regional Collaborative Governance of Air Pollution-Based on the Cooperative Practice of Jing-Jin-Ji Region. China Soft Sci. 2018, 10, 79-92.

30. Yang, L.; Gao, H. Whether Economic Growth Will Automatically Solve the Environmental Problems?-Inverted U-shaped Environmental Kuznets Curve is the Result of Endogenous Mechanisms or External Control Results. China Popul. Resour. Environ. 2012, 22, 160-165.

31. Li, J.; Jin, Z.; Yuan, Q. Beijing-Tianjin-Hebei Air Quality Environment Kuznets Curve and Influencing Factors: An Analysis Based on Panel Data from 2006 to 2017. Ecol. Econ. 2019, 35, 197-201.

32. Tao, J.; Hu, X. Research on the effects of environmental regulation on the quality of China's economic growth. China Popul. Resour. Environ. 2019, 29, 85-96. 